\title{
Design and Structural Analysis of Fighter Aircraft's Bomb Release Mechanism subjected to Aerodynamic and Inertial Loads using FEA
}

\author{
Sindura.S ${ }^{1 *}$ and Raja Singh Thangadurai.$G^{2}$ \\ ${ }^{1}$ Senior Project Fellow,National Aerospace Laboratory,Bangalore, India \\ ${ }^{2}$ Scientist- ' $G$ ', Project Director, PJ-10(DAV), Defense Research and Development Laboratory, Hyderabad, India \\ *Corresponding author E-mail:sindura3192@gmail.com
}

\begin{abstract}
This work speaks about the advancement of the design of a bomb rack unit's component, to carry out the ideal execution for the ejection of the bomb from a supporting body where the suspension, separation, and ejection of the store are decidedly organized and controlled. Initially, the aircraft bomb rack unit (BRU) was examined hypothetically. The structure of the bomb rack unit is designed considering the military standards. Nitty-gritty investigation was performed for the critical case, capacity and reaction of the BRU among the stacking blends using the Finite Element Method for Static and dynamic conditions and corresponding results were illustrated.
\end{abstract}

Keywords: Static Structural Analysis ; Dynamic Structural Analysis ; Finite Element Analysis ; Structural Design ; CAE \& Simulation

\section{Nomenclature}

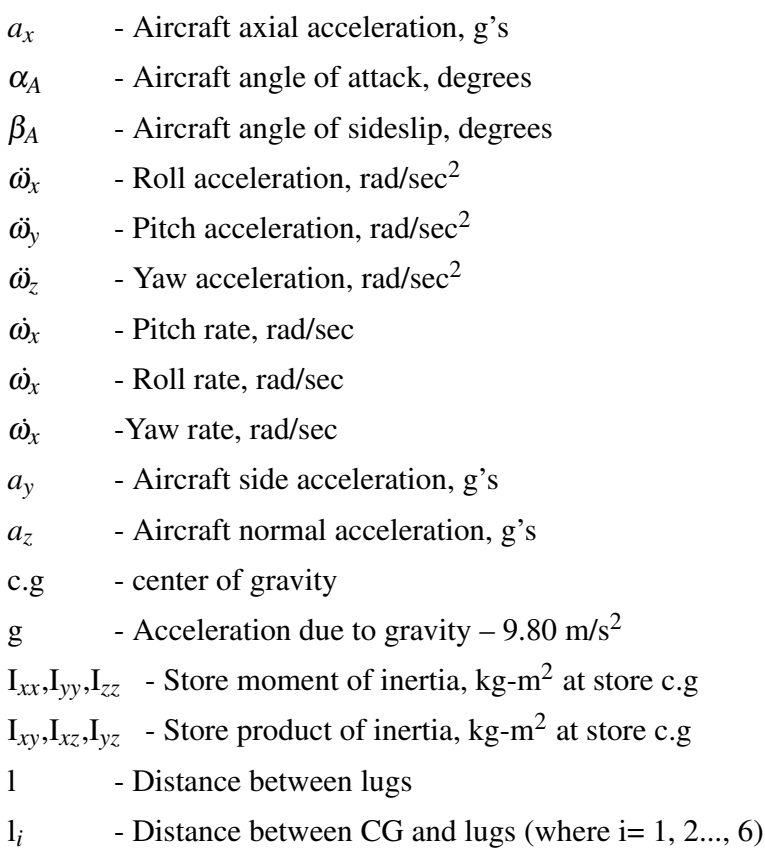

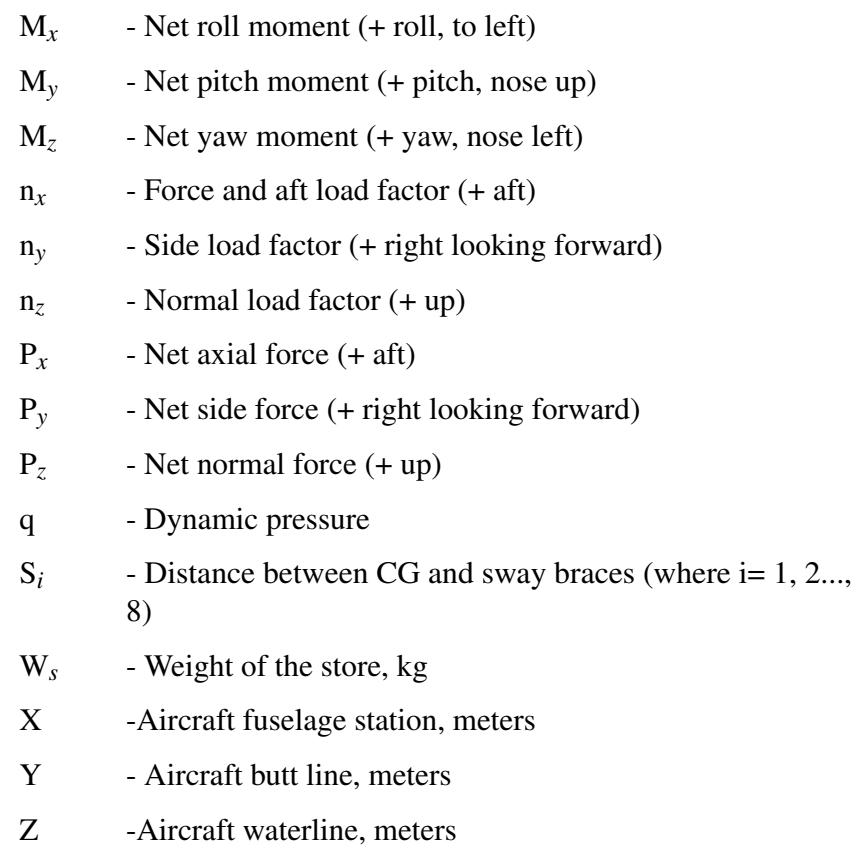




\section{Introduction}

There is a long-standing interest in the design and development of the external ordinances of military aircraft, Bomb Rack Unit (BRU). In Military aircraft, racks are located beneath the wings and fuselage to carry and dispense the store upon command. Conventionally, a BRU as shown in Figure. 1 includes ejectors, sway braces, release mechanism which is activated to mechanically release and subsequently, forcibly eject the stores from the aircraft. Sway brace is a physical tri-axial restraint system. It is assembled by means of self-adjusting wedges. Its function is to support and react partially/ totally to the store moment in addition to the store loads. The ejector unit uses the pneumatic system to generate the required pressure for rack operation, so that, it ejects the store from the rack with sufficient force to overcome vacuum build-up under the fuselage and wings of aircraft in high speeds. The support frame acts as a dome to the entire setup of the bomb release mechanism and its function is to protect the equipment from the environment. It has pins, which are located beneath the frame. Pins are inserted into the holes on the upper surface of the store (bomb). This is done to ensure that the store is loaded properly without any misalignment. According to Harvey Stewart et. al[1] a design of release mechanism which carries stores and can be loaded

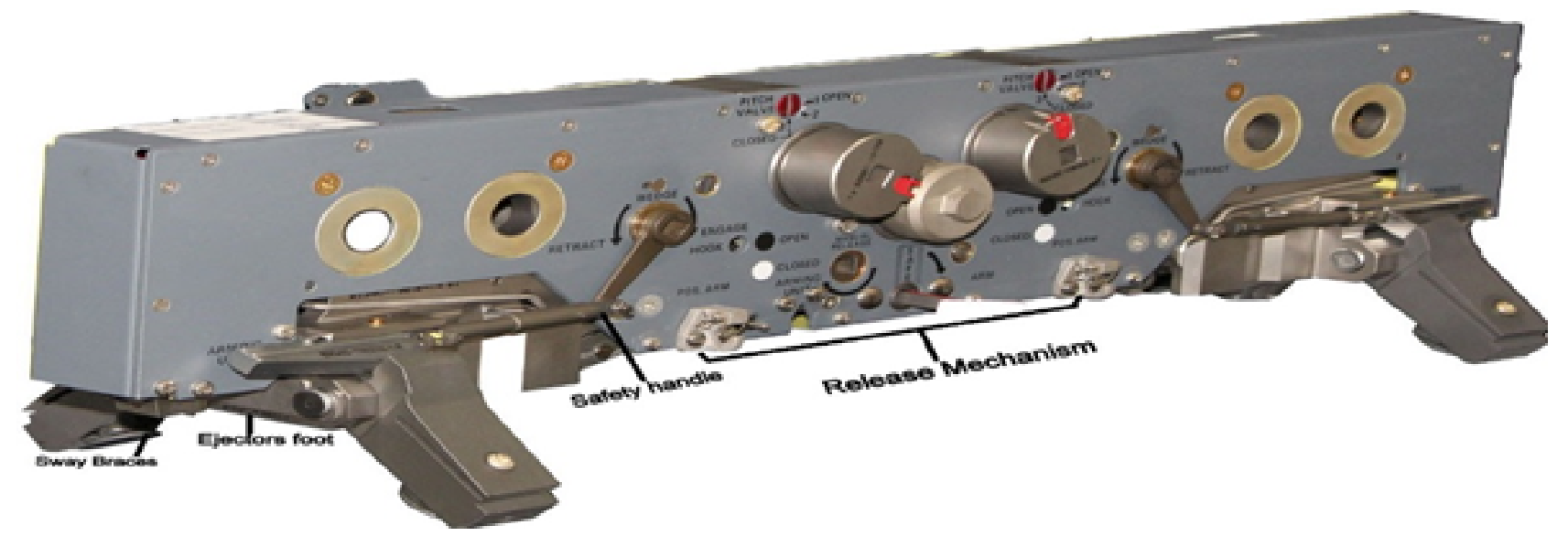

Figure 1: External View of BRU

easily and has a substantial mechanical advantage to assure sufficient store release force. Paul F.Peterson et al [2] invention relates to ejector rack for carrying a store and it has novel features like low ejection velocity. Thaddews Jakubowski [3] invention of design provides a store carrier rack with automatic sway bracing between store retaining hooks. Steven D.Kay [4] invention relates to the low force bomb rack release mechanism. Jean H.Hasqueonoph [5] et.al invention relates in general to means of locking loads carried under aircraft in relation to fixed supports. TMC.Schopert [6] has analyzed the performance of BRU by building a test facility to simulate the inertial forces acting on an external force.

\subsection{Technical Requirements}

The requirements based on typical store specification as given below:

1. Length $=3050 \mathrm{~mm}$; diameter $=380 \mathrm{~mm}$; weight $=500 \mathrm{~kg} ;$ CG location from nose $=1500 \pm 100 \mathrm{~mm}$; distance between suspension lugs $=$ $360 \mathrm{~mm}$

2. The bomb rack unit should be universal i.e., for all stations $2,5,6,7 \& 8$ of aircraft.

3. Dimensions $1500(\mathrm{~L}) \times 200(\mathrm{~W}) \times 300(\mathrm{H}) \mathrm{mm}$.

4. The mass of the rack unit shall not be weighed more than $120 \mathrm{~kg}$.

5. The distance between suspension points of the bomb rack unit to the existing adapter beam shall be maintained at $1150 \pm 1 \mathrm{~mm}$.

6. There shall be an electro-mechanical mechanism for the opening of the hooks for releasing the store.

7. Two units of clutches should be synchronized mechanically to avoid unsymmetrical opening during release and shall have a provision for the manual opening and closing of the clutches on the ground prior to loading the article.

8. The hooks should remain in open condition after the release of the store until it is manually driven.

9. It should be designed to withstand inertial loads with yield factor of safety of 1.15 on the limit and ultimate factor of safety of 1.5 on the limit.

\subsection{Certification Criteria}

The constraints as discussed in Table.1 were modified to improve the design of the mechanism for better performance. So that, it confirms to the Military standards of BRU:

- MIL-STD-8591 [7]: This standard sets forth general structural and mechanical design criteria for airborne stores, suspension equipment, and their associated interfaces.

- MIL-STD-8591H [8]: This standard is extension of MIL-STD-8591H. It contains general criteria for the design, analysis, and testing of airborne stores, suspension equipment and other details of the interface between the store and the aircraft suspension equipment.

- MIL-STD-2088A [9]: This standard establishes the general guidelines and criteria for the design and development of the bomb rack unit for carriage and power-ejection release of airborne stores on standard 14-inch or 30-inch suspension from fixed-wing aircraft. Mechanical aircraft armament inter-operable interfaces are incorporated to enhance cross-utilization and servicing capabilities between military aircraft and aircraft stores of all services of the department of defense. 
Table 1: List of Constraints of the referred Bomb Release Mechanism

\begin{tabular}{|c|l|l|}
\hline S.No. & Constraints of the device & Commentary \\
\hline 1 & $\begin{array}{l}\text { Rotating the stretching device in } \\
\text { one direction. }\end{array}$ & $\begin{array}{l}\text { The cylindrical member comprising the radial holes must be rotated through a } \\
\text { relatively great number of revolutions for obtaining an appreciable movement } \\
\text { of hooks. }\end{array}$ \\
\hline 2 & $\begin{array}{l}\text { Screw-type stretching device } \\
\text { adapted to be actuated by means } \\
\text { cylindrical member }\end{array}$ & $\begin{array}{l}\text { Cylindrical member was provided with radial holes engage-able by a screw- } \\
\text { driver, rod, and other tools. Due to the necessity of making the load device } \\
\text { irreversible, the stretching device comprises fine-pitch, likewise irreversible } \\
\text { threads. }\end{array}$ \\
\hline 3 & $\begin{array}{l}\text { Equal forces exerted on the suspen- } \\
\text { sion hooks }\end{array}$ & $\begin{array}{l}\text { Equal forces are exerted on the hooks; This control is obtained by the assis- } \\
\text { ance of an ordinary stretching device, in which forces resulting from the } \\
\text { pre-stress exerted on the hooks are equally distributed. }\end{array}$ \\
\hline 4 & $\begin{array}{l}\text { Distance from the central rocker to } \\
\text { center of suspension hooks are the } \\
\text { same on either side, it is assembled } \\
\text { with symmetrical distance concept. }\end{array}$ & $\begin{array}{l}\text { The distances between the centers of suspension hooks are standardized. The } \\
\text { connecting rods, links are all of the same dimensions and space required } \\
\text { for the assembling them is up to the standardized limit due to symmetrical } \\
\text { concept. }\end{array}$ \\
\hline \multicolumn{2}{|l}{}
\end{tabular}

\section{Methodology}

A detailed flow chart in Figure. 2 illustrates the work flow. Considering the constraints, the development of this device is made as follows:

- Central rocker rotation is reduced from existing $90^{\circ}$ to $75^{\circ}$ and it is operated with a torque motor, thereby reducing the energy required to rotate.

- The stretching device or screw is replaced with a cylinder and piston arrangement which is operated by a pneumatic system. Center rocker is actuated by torque motor.

- Then connecting rods which are pivoted to central rocker are unsymmetrical in length. The entire setup of the mechanism is, therefore unsymmetrical about the central rocker axis.

- The unit's equipment is covered by a rectangle-shaped dome. Dome upper surface has lugs spaced according to a specification that is used for attachment with the pylon and the lower surface of the dome has fixed pin-like structures that are inserted into the slots on the store for preventing forwards forces and to ensure that bomb is located perfectly without any misalignment.

\section{Design and Analysis}

\subsection{Design}

Following procedure is followed for modelling 3D geometry of the BRM:

1. 2D geometry of the modified Bomb release mechanism.

In Figure.3, EFG represents central rocker. ED \& GH represents connecting rods. CD \& KH represents vertical links. HI \& DA represents horizontal links. LKJ \& MCB represents bell cranks. AB \& JI represents suspension hooks.

2. It has 7 binary joints and 4 ternary joints.

(a) To determine the nature of chain i.e. whether the chain is a locked chain or kinematic chain or unconstrained chain, Equation (1) given by A.W.Klein, was used [10]:

$J=\frac{3}{2} L-2$

Where $\mathrm{J}=$ number of binary joints; $\mathrm{L}=$ number of links. Here, $\mathrm{L}=14$ and $\mathrm{J}=7+(4 \times 3)=19$; substituting $\mathrm{J}$ and $\mathrm{L}$ values in above equation, we get $19=19$. We can see that L.H.S $=$ R.H.S, therefore the chain is a kinematic chain or constrained chain.

(b) Number of degree of freedom for the mechanism is given by relation shown in eq. 2 \& eq. 3

$n=3(l-1)-2 j$

$n=3(14-1)-2(19)=1$

When $\mathrm{n}=1$, then the mechanism can be driven by a single input motion.

3. Dimensions of the links were fixed and checked for enough clearance. According to MIL-STD-8291, for 500kg bomb weight, the spacing between centers of lugs and hooks should be 14-inches. Therefore spacing between lug and hook is $355.6 \mathrm{~mm}$ and the sway brace is $127-203 \mathrm{~mm}$. The minimum area per sway brace is 1290 sq.mm.Aircraft considered here was Su- 30 .

4. CAD Model: Finally, the CAD 3D model of the mechanism was generated with effective to above mentioned modifications using CATIA and was shown in Figure.4 and Figure.5. 


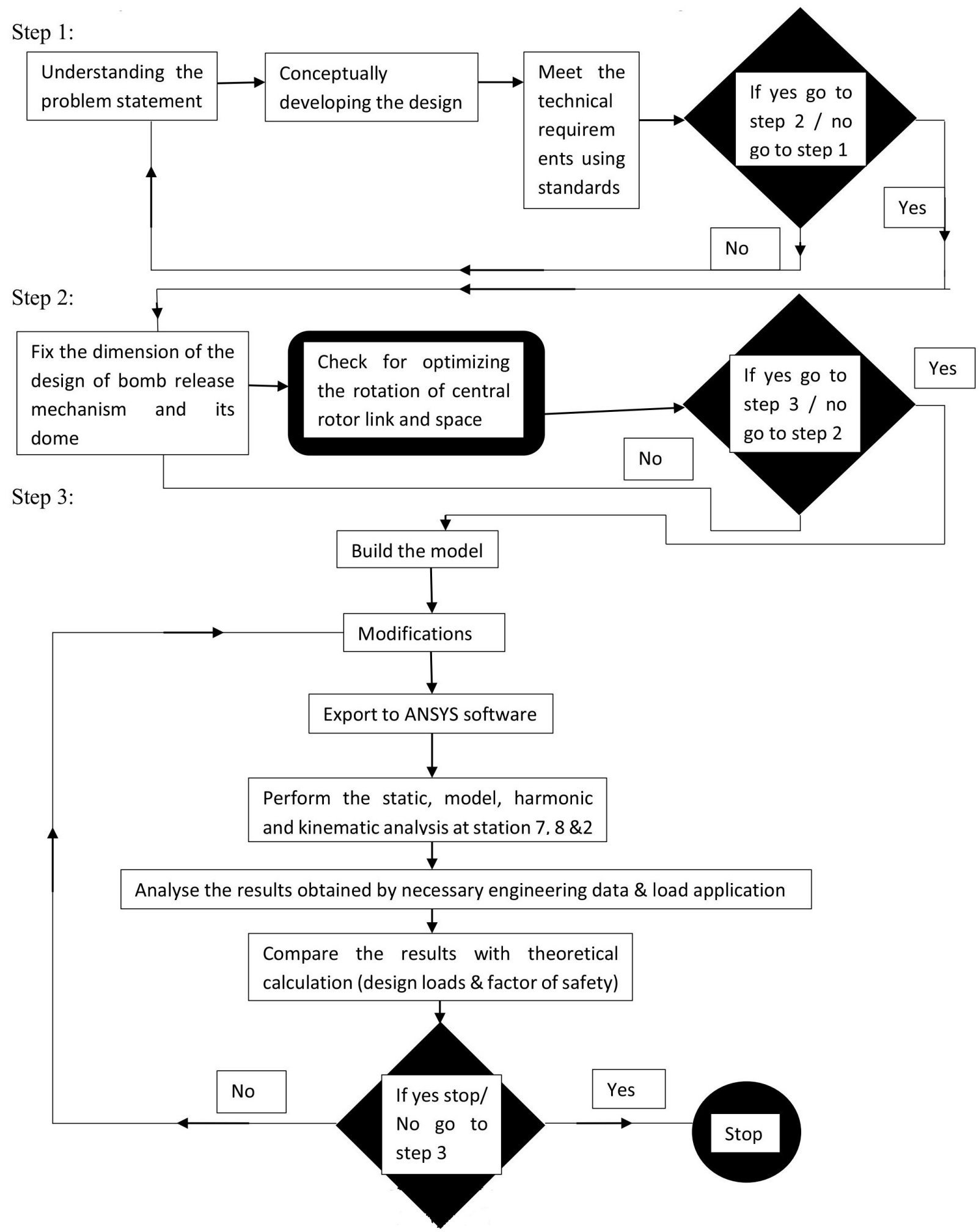

Figure 2: Flowchart of the Methodology

\subsection{Calculations}

The developed design should have the strength and rigidity to support the forces and moments resulting from the loading conditions. Appendix-b and d of MIL-STD-8959H [8], are considered to calculate inertia loads and maximum reaction forces. The empirical formulae and calculations are described in this subsection.

Inertia Loads:

Inertia loads are determined from a knowledge of the aircraft performance capabilities and the location of the store on the aircraft. Each 

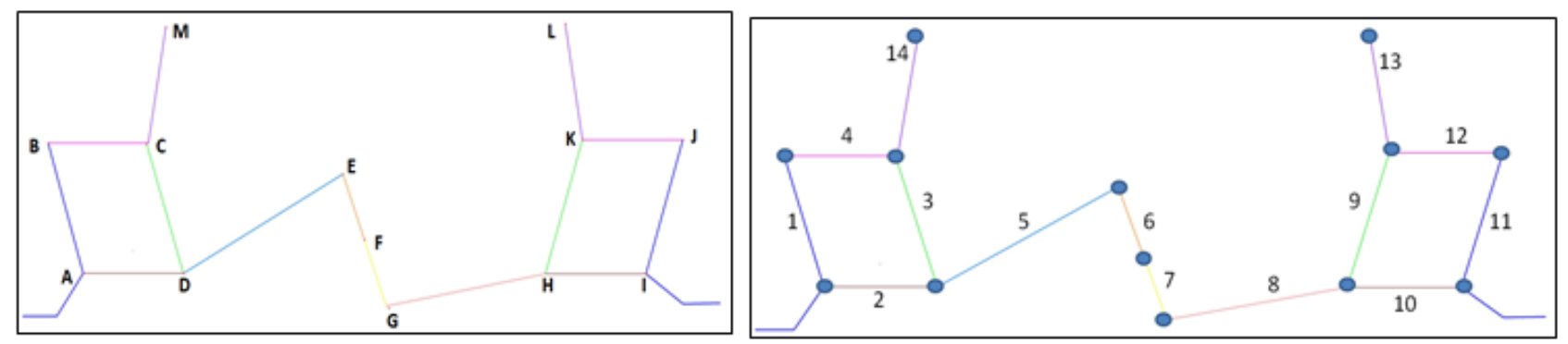

Figure 3: 2D geometry showing Links and Joints of BRM

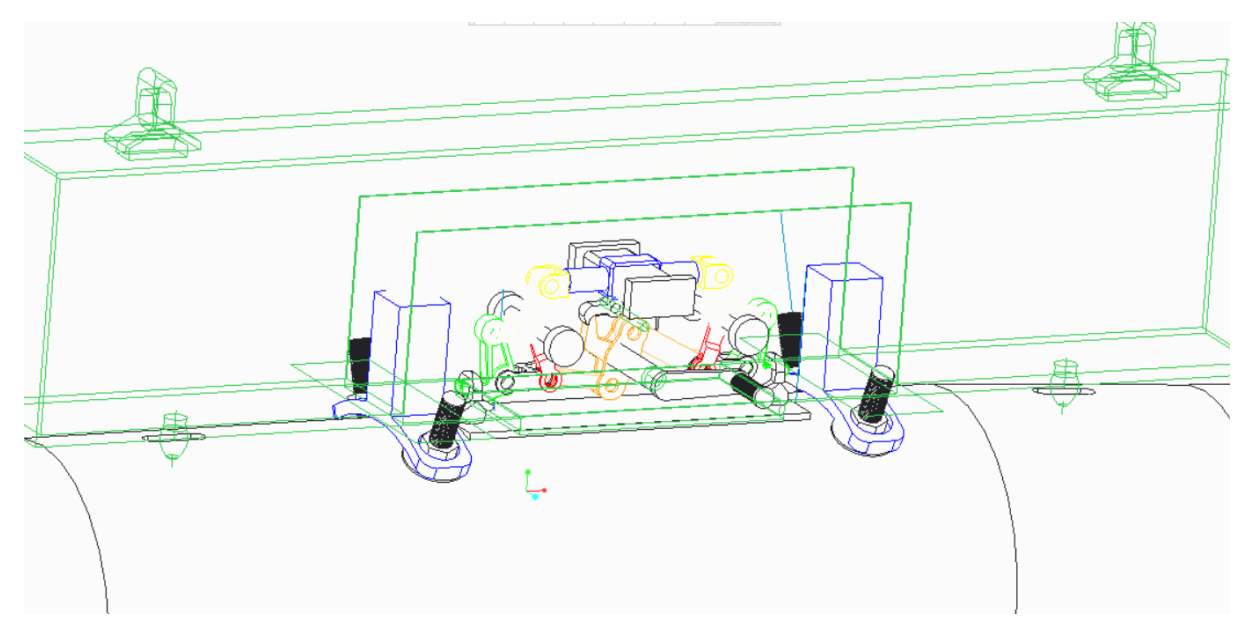

Figure 4: Geometric view showing pins of supporting frame which was inserted into the Bomb

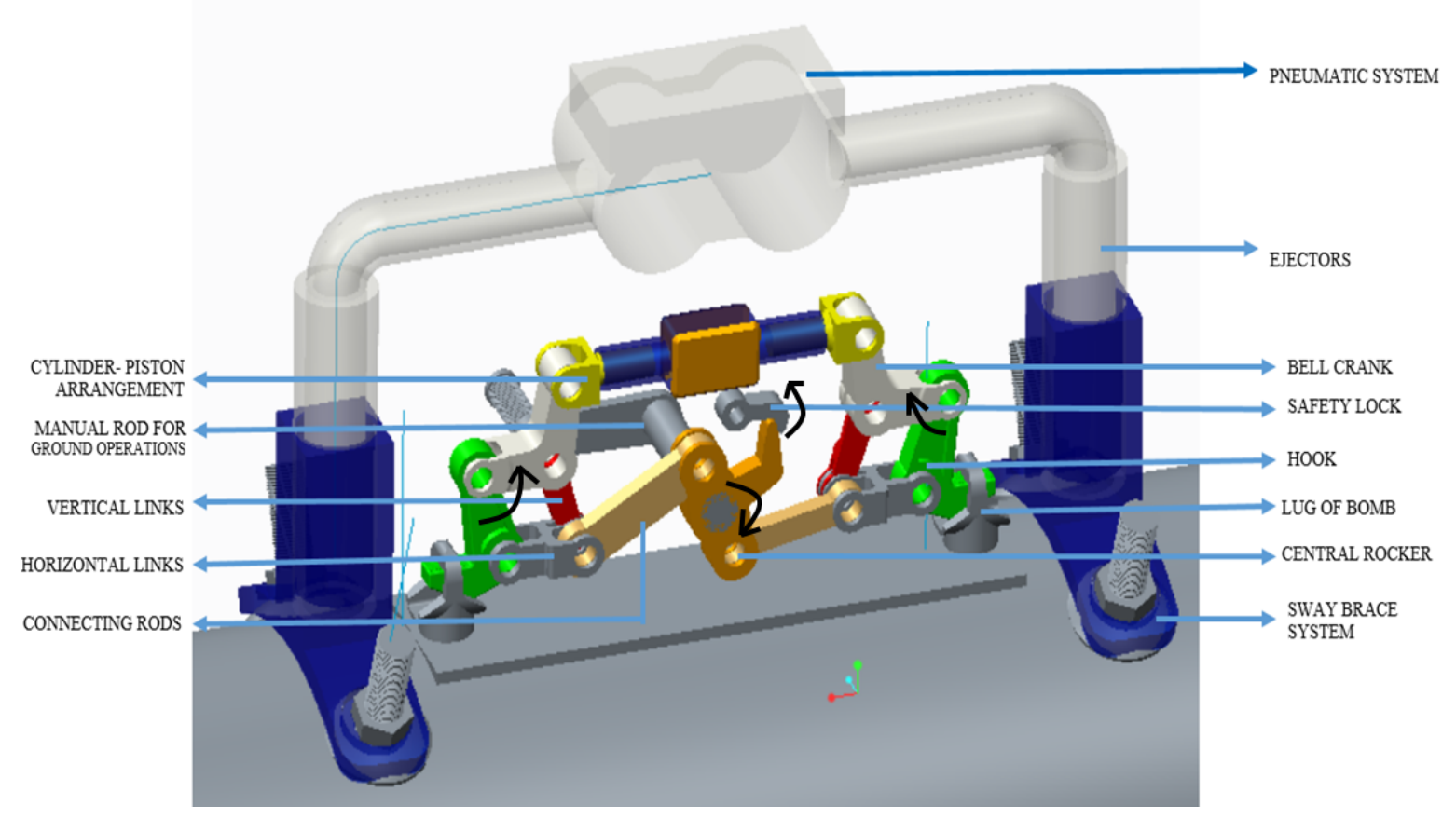

Figure 5: Developed Bomb Release Mechanism with sway braces and ejector unit

combination of aircraft and carriage location defined by the acquiring activity shall be considered in determining the critical loads. When the performance capability of the aircraft is affected by the presence of the store, the performance with the store is used. These load factor envelopes are applied at the store C.G. It shall be noted that the store load factors are equal in magnitude, but opposite in direction to the acceleration in units of gravity ( $\mathrm{g}$ 's) experienced by the store during a particular maneuver[8].

The load factors are computed using the relations given below and Table.2. The description of the terms used in the equations is given in the nomenclature. 
$\Delta Y=Y_{\text {storec.g }}-Y_{\text {aircraftc.g }}$

$\Delta Z=Z_{\text {storec.g }}-Z_{\text {aircraftc.g }}$

\subsubsection{Load factor Equations}

$n_{x}=-a_{x}+\frac{1}{g}\left[\dot{\omega}_{z} \Delta Y-\dot{\omega}_{y} \Delta Z+\left(\dot{\omega}_{y}^{2}+\dot{\omega}_{z}^{2}\right) \Delta X-\left(\dot{\omega}_{x} \dot{\omega}_{y}\right) \Delta Y-\left(\dot{\omega}_{x} \dot{\omega}_{z}\right) \Delta Z\right]$

$n_{y}=-a_{y}+\frac{1}{g}\left[\dot{\omega}_{x} \Delta Z-\dot{\omega}_{z} \Delta X+\left(\dot{\omega}_{x}^{2}+\dot{\omega}_{z}^{2}\right) \Delta Y-\left(\dot{\omega}_{x} \dot{\omega}_{y}\right) \Delta X-\left(\dot{\omega}_{y} \dot{\omega}_{z}\right) \Delta Z\right]$

$n_{z}=-a_{z}+\frac{1}{g}\left[\dot{\omega}_{y} \Delta X-\dot{\omega}_{x} \Delta Y+\left(\dot{\omega}_{y}^{2}+\dot{\omega}_{x}^{2}\right) \Delta Z-\left(\dot{\omega}_{x} \dot{\omega}_{z}\right) \Delta X-\left(\dot{\omega}_{y} \dot{\omega}_{z}\right) \Delta Y\right]$

\subsubsection{Force Equations}

$P_{x_{\text {inertia }}}=n_{x} W_{s}$

$P_{y_{\text {inertia }}}=n_{y} W_{s}$

$P_{z_{\text {inertia }}}=n_{z} W_{s}$

\subsubsection{Moment Equations}

$M_{x_{\text {inertia }}}=-I_{x x} \ddot{\omega}_{x}+\left(I_{y y}-I_{z z}\right) \dot{\omega}_{y} \dot{\omega}_{z}+I_{y z}\left(\dot{\omega}_{y}^{2}-\dot{\omega}_{z}^{2}\right)+I_{x z}\left(\ddot{\omega}_{z}+\dot{\omega}_{x} \dot{\omega}_{y}\right)+I_{x y}\left(\ddot{\omega}_{y}-\dot{\omega}_{x} \dot{\omega}_{z}\right)$

$M_{y_{\text {inertia }}}=-I_{y y} \ddot{\omega}_{y}+\left(I_{z z}-I_{x x}\right) \dot{\omega}_{x} \dot{\omega}_{z}+I_{x z}\left(\dot{\omega}_{z}^{2}-\dot{\omega}_{x}^{2}\right)+I_{x y}\left(\ddot{\omega}_{x}+\dot{\omega}_{y} \dot{\omega}_{z}\right)+I_{y z}\left(\ddot{\omega}_{z}-\dot{\omega}_{x} \dot{\omega}_{y}\right)$

$M_{z_{\text {inertia }}}=-I_{z z} \ddot{\omega}_{z}+\left(I_{x x}-I_{y y}\right) \dot{\omega}_{x} \dot{\omega}_{y}+I_{x y}\left(\dot{\omega}_{x}^{2}-\dot{\omega}_{y}^{2}\right)+I_{y z}\left(\ddot{\omega}_{y}+\dot{\omega}_{x} \dot{\omega}_{z}\right)+I_{x z}\left(\ddot{\omega}_{x}-\dot{\omega}_{y} \dot{\omega}_{z}\right)$

\section{Maximum Reaction Forces:}

Here, the reaction forces at sway brace (SB)/ store SB pads and hooks/lugs of a store equipment configuration was calculated. Store pads take compression loads only. The hooks/lugs take tension loads only in the vertical direction.

Since the four SB's/store SB pads and the two hooks/lugs are designed to withstand their respective maximum forces, only the combination of the external loads that results in these maximum reaction forces at each SB/store SB pad and each hook/lug, as shown in Table 3 was considered.

Let us consider the relation of static equilibrium $\Sigma F_{i}=0$ and $\Sigma M_{i}=0$ in all three planes, X-Y, Y-Z, and X-Z. Through, the principle of superposition and the combinations of forces and moments of Table 3, the following equations were derived using Figure.6 [8]. The terms in the equations are described in nomenclature.

\subsubsection{Equations for the forward left or right store sway brace pad}

$s_{y}=s_{z} \tan \varepsilon$

$s_{z}=A P_{x}+B P_{y}+C P_{z}+D M_{x}+E M_{y}+F M_{z}$

$s=s_{z} / \cos \varepsilon$

Where,

$A=l_{5} / 2\left(s_{1}+l_{2}\right)+l_{3} /$ stan $\varepsilon ; B=s_{2} l_{5} / s k$;

$C=\left(s_{2} / s\right)\left(0.5+l_{3} / k\right) ; D=s_{2} / s k ; E=0.5 /\left(s_{1}+l_{2}\right)$;

$F=1 / \operatorname{stan} \varepsilon ; H=\left(l_{5}-s_{5}\right)$ tan $; k=H+\left(l_{3}+s_{3}\right)$ 
Table 2: Aircraft flight conditions for design of stores on high performance aircraft (limit loads) [8]

\begin{tabular}{|c|c|c|c|c|c|c|c|c|c|c|c|c|c|}
\hline \multirow[t]{2}{*}{ Conditions } & \multirow[t]{2}{*}{$\begin{array}{l}\text { Dynamic } \\
\text { Pressure } \\
(\mathrm{psf})\end{array}$} & \multicolumn{2}{|c|}{$\begin{array}{l}\text { Aircraft } \\
\text { Angles } \\
\text { (deg) }\end{array}$} & \multicolumn{3}{|c|}{$\begin{array}{l}\text { Linear acceleration } \\
(\mathrm{g})\end{array}$} & \multicolumn{3}{|c|}{$\begin{array}{l}\text { Peak angle rates } \\
(\mathrm{rad} / \mathrm{sec})\end{array}$} & \multicolumn{3}{|c|}{$\begin{array}{l}\text { Peak angular } \\
\text { accelerations } \\
(\mathrm{rad} / \mathrm{sec})\end{array}$} & \multirow[t]{2}{*}{ 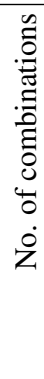 } \\
\hline & & $\begin{array}{l}\text { Att } \\
\text { ack } \\
\alpha_{A}\end{array}$ & $\begin{array}{l}\text { Side } \\
\text { slip } \\
\beta_{A}\end{array}$ & $a_{x}$ & $a_{y}$ & $a_{z}$ & $\dot{\omega}_{x}$ & $\dot{\omega}_{y}$ & $\dot{\omega}_{z}$ & $\ddot{\omega}_{x}$ & $\ddot{\omega}_{y}$ & $\ddot{\omega}_{z}$ & \\
\hline 1.Pullout & 2500 & 5 & 0 & \pm 1.5 & \pm 1.0 & 7 & 0 & 0 & 0 & \pm 0.25 & \pm 0.5 & 0 & 16 \\
\hline 2.Pullout & 1000 & 13 & 0 & \pm 1.5 & \pm 1.0 & 8.5 & 0 & 0 & 0 & \pm 0.5 & \pm 0.5 & 0 & 16 \\
\hline 3.Pullout & 500 & 25 & 0 & \pm 1.5 & \pm 1.0 & 10 & 0 & 0 & 0 & \pm 0.5 & \pm 0.5 & 0 & 16 \\
\hline $\begin{array}{l}\text { 4.Rolling- Pull- } \\
\text { out }\end{array}$ & 650 & 6 & 2 & \pm 1.5 & \pm 0.5 & 7 & \pm 5.0 & 0 & 0 & \pm 11.0 & \pm 3.0 & \pm 2.0 & 64 \\
\hline $\begin{array}{l}\text { 5.Rolling- Pull- } \\
\text { out }\end{array}$ & 2500 & 3 & 1 & \pm 1.5 & \pm 0.25 & 6.5 & \pm 4.5 & 0 & 0 & \pm 13.0 & \pm 1.0 & \pm 1.0 & 64 \\
\hline $\begin{array}{l}\text { 6.Rolling- Pull- } \\
\text { out }\end{array}$ & 2500 & 2 & 1 & \pm 1.5 & \pm 0.25 & 6 & \pm 4.5 & 0 & 0 & \pm 17.0 & \pm 1.0 & \pm 1.0 & 64 \\
\hline $\begin{array}{l}\text { 7.Barrier engage- } \\
\text { ment(land) }\end{array}$ & 150 & 0 & 0 & -4 & \pm 1.0 & 2 & 0 & 0 & 0 & 0 & \pm 6.0 & \pm 4.0 & 8 \\
\hline $\begin{array}{l}\text { 8.Max sink rate } \\
\text { landing }\end{array}$ & 150 & 0 & 0 & -1 & \pm 1.0 & 4 & 0 & 0 & 0 & 0 & \pm 4.0 & \pm 2.0 & 8 \\
\hline $\begin{array}{l}\text { 9.Bank-to-bank } \\
\text { roll }\end{array}$ & 2500 & 3 & 1 & \pm 1.5 & \pm 1.0 & 6 & 0 & 0 & 0 & \pm 13.0 & \pm 0.5 & \pm 1.0 & 32 \\
\hline $\begin{array}{l}\text { 10.Rudder kick } \\
\text { release }(1 \mathrm{~g})\end{array}$ & 400 & 2 & 10 & \pm 1.5 & \pm 1.5 & 1 & 0 & 0 & 0 & \pm 1.0 & 0 & \pm 1.5 & 16 \\
\hline 11.Pushover & 2500 & -2 & 0 & \pm 1.5 & \pm 1.0 & -1 & 0 & 0 & 0 & 0 & 0 & 0 & 4 \\
\hline 12.Pushover & 1800 & -4 & 0 & \pm 1.5 & \pm 1.0 & -3 & 0 & 0 & 0 & 0 & 0 & 0 & 4 \\
\hline 13.Pushover & 1000 & -6 & 0 & \pm 1.5 & \pm 1.0 & -6 & 0 & 0 & 0 & \pm 0.5 & 0 & 0 & 8 \\
\hline
\end{tabular}

Table 3: Direction of external loads \& moments for maximum reaction forces at the SB/ store SB pads and Hook/Lugs [8]

\begin{tabular}{|c|c|c|c|c|c|c|}
\hline \multirow{2}{*}{ Loads } & \multicolumn{4}{|c|}{ SB/store SB pad } & \multicolumn{2}{c|}{ Hook/Lug } \\
\cline { 2 - 7 } & \multicolumn{2}{|c|}{ Fwd. } & \multicolumn{2}{c|}{ Aft. } & \multirow{2}{*}{ Aft. } \\
\cline { 2 - 7 } & Left & Right & Left & Right & Fwd. & A \\
\hline$P_{x}$ & - & - & + & + & + & - \\
$P_{y}$ & - & + & - & + & \pm & \pm \\
$P_{z}$ & + & + & + & + & - & - \\
$M_{x}$ & - & + & - & + & \pm & \pm \\
$M_{y}$ & + & + & - & - & - & \pm \\
$M_{z}$ & + & - & - & + & \pm & \pm \\
\hline
\end{tabular}

\subsubsection{Equations for the aft left or right sway brace pad}

$s_{y}=s_{z} \tan \varepsilon$

$s_{z}=A P_{x}+B P_{y}+C P_{z}+D M_{x}+E M_{y}+F M_{z}$

$s=s_{z} / \cos \varepsilon$

Where ,

$A=l_{5} / 2\left(s_{2}+l_{1}\right)+l_{3} /$ stan $\varepsilon ; B=s_{1} l_{5} / s k ;$

$C=\left(s_{1} / s\right)\left(0.5+l_{3} / k\right) ; D=s_{1} / s k ; E=0.5 /\left(s_{2}+l_{1}\right)$;

$F=1 / \operatorname{stan} \varepsilon ; H=\left(l_{5}-s_{5}\right)$ tan $; k=H+\left(l_{3}+s_{3}\right)$

\subsubsection{Equations for the forward hook/lug}

$L_{x}=P_{x}$ 

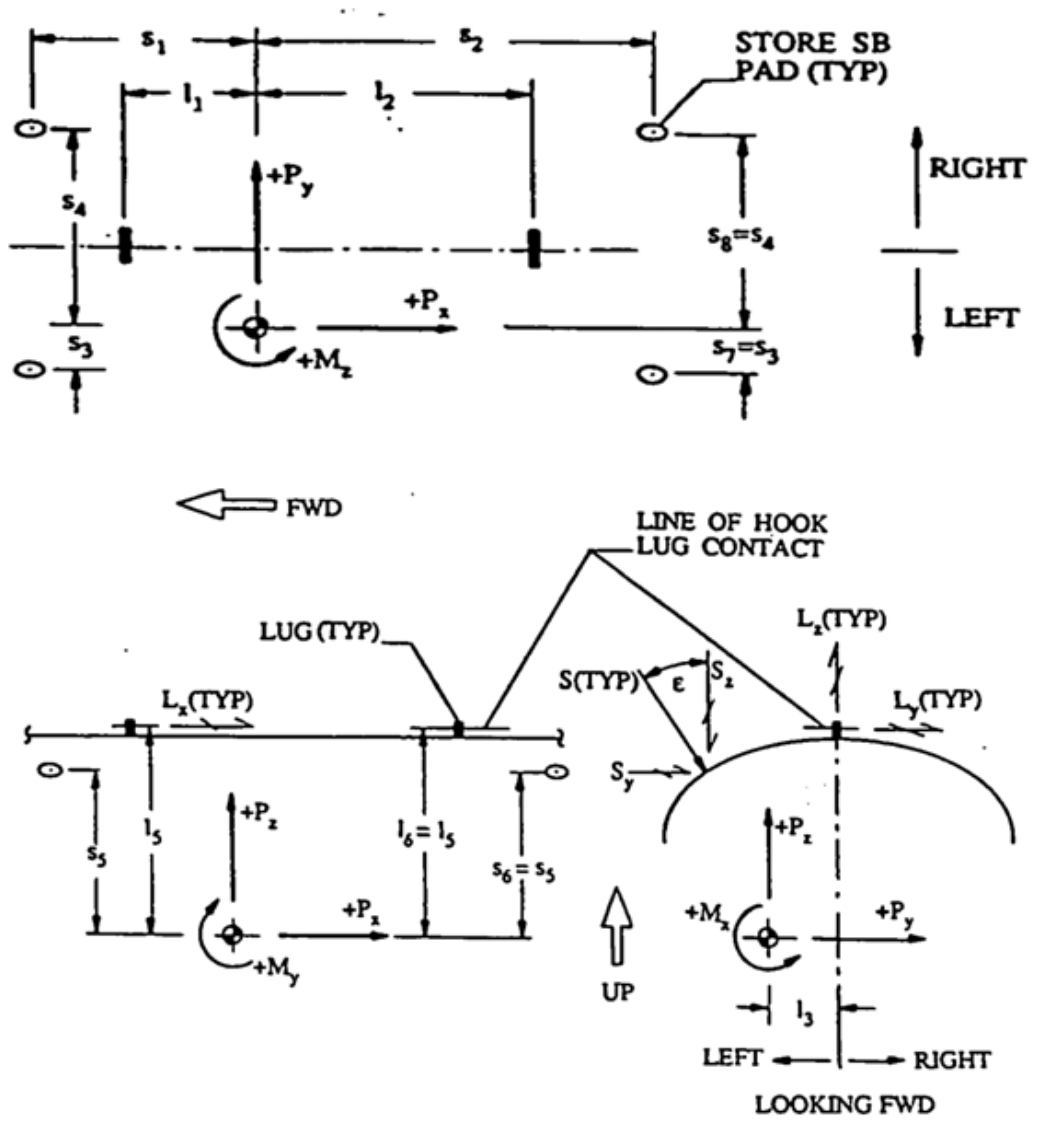

Figure 6: System of coordinates and sign convention

$L_{y}=B_{y} P_{y}+C_{y} P_{z}+D_{y} M_{x} ; A_{y}=E_{y}=F_{y}=0$

Where,

$B_{y}=\left(s_{2} / s\right)\left[\left(l_{5}\right.\right.$ tan $\left.\left.\varepsilon / k\right)-1\right] ; C_{y}=l_{2} l_{3}$ tan $\varepsilon /\left[l\left(H+s_{4}-l_{3}\right)\right]$;

$D_{y}=s_{2}$ tan $\varepsilon / s k ; l_{z}=A_{z} P_{x}+B_{z} P_{y}+C_{z} P_{z}+D_{z} M_{x}+E_{z} M_{y}+F_{z} M_{z}$;

Where,

$A=l_{5} / 2\left(s_{2}+l_{1}\right)+l_{3} / \operatorname{stan} ; B=s_{2} l_{5} / s k ; F=1 /$ stan $\varepsilon ;$

$C_{z}=\left(\frac{l_{2}}{l}\right)\left[\frac{l_{3}}{H+s_{4}-l_{3}}+1\right] ; D=s_{2} / s k ; E=1 /\left(s_{2}+l_{1}\right)$.

\subsubsection{Equations for the aft hook/ lug}

$L_{x}=P_{x}$

$L_{y}=B_{y} P_{y}+C_{y} P_{z}+D_{y} M_{x} ; A_{y}=E_{y}=F_{y}=0$

Where,

$B_{y}=\left(s_{1} / s\right)\left[\left(l_{5}\right.\right.$ tan $\left.\left.\varepsilon / k\right)-1\right] ; C_{y}=l_{1} l_{3}$ tan $\varepsilon /\left[l\left(H+s_{4}-l_{3}\right)\right]$;

$D_{y}=s_{1} \tan / s k ; l_{z}=A_{z} P_{x}+B_{z} P_{y}+C_{z} P_{z}+D_{z} M_{x}+E_{z} M_{y}+F_{z} M_{z}$;

Where,

$A=l_{5} / 2\left(s_{1}+l_{2}\right)+l_{3} / \operatorname{stan} \varepsilon ; B=s_{1} l_{5} / s k ; F=1 / \operatorname{stan} \varepsilon ;$

$C_{z}=\left(\frac{l_{1}}{l}\right)\left[\frac{l_{3}}{\left(H+s_{4}-l_{3}\right)}+1\right] ; D=s_{1} / s k ; E=1 /\left(s_{1}+l_{2}\right)$.

These whole procedures are calculated at stations 2,5,6,7 and 8 . Where in, station 2 which was located beneath the fuselage and station 7,8 located beneath wing tips are considered.The forces at station 7,8 (critical case) was considered and presented as follows:

1. Forward sway brace: $\left.s_{(} z\right)=1598.60 N ; s_{y}=728.86 N ; L_{y}=823.33 N$

2. Aft ward Sway brace: $s_{z}=4330.34 N ; s_{y}=1974.36 N ; L_{y}=823.33 N$

3. Forward Hook: $L_{z}=9032.23 \mathrm{~N}$

4. Aft ward Hook: $L_{z}=14250.49 \mathrm{~N}$

5. Outer dome forward pin: $L_{x}=3116.327 N ; L_{y}=823.33 N$ 
6. Outer dome aft ward pin: $L_{x}=1191.837 N ; L_{y}=823.33 N$

\subsection{Analysis}

The FE method is much more effective in handling the complexities associated with the structure and its behavior in 3D. The performance, capability, and response of the bomb release mechanism (Figure .5) and supporting frame( Figure.4) are developed using ANSYS FE package [11]. Bomb release mechanism and main loading bearing members(lugs \& pins) of supporting frame was modeled with Grade 250 maraging steel and aluminum alloy is the material of construction for other associated structures. The elements considered for the modeling and Method followed is shown in Table.4. In mesh sizing, fine relevance center and medium smoothing are considered, the element size was 1.3 $\mathrm{mm}$.

\subsection{Material properties}

Mechanical properties of materials used are given in Table 5 .

Table 4: List of Elements in FE model

\begin{tabular}{|c|c|c|}
\hline \multicolumn{3}{|c|}{ Elements used in the FE Analysis } \\
\hline Object name & Method & Element type \\
\hline Central rotor & Hexa dominant & Quad \\
Connecting rods & Hexa dominant & Quad \\
Horizontal links & Hexa dominant & Quad \\
Vertical links & Hexa dominant & Quad \\
Piston & Hexa dominant & Quad \\
Cylinder & Hexa dominant & Quad \\
Hooks & Multi-zone & tetra \\
Bell cranks & Multi-zone & tetra \\
\hline
\end{tabular}

Table 5: Mechanical properties of materials

\begin{tabular}{|c|c|c|c|}
\hline S.No. & Mechanical Properties & Aluminum alloy & Grade 250 maraging steel \\
\hline 1 & Compressive strength & 760 to $1600 \mathrm{MPa}$ & 760 to $1600 \mathrm{MPa}$ \\
2 & Density & $2770 \mathrm{~kg} / \mathrm{m}^{3}$ & $8000 \mathrm{~kg} / \mathrm{m}^{3}$ \\
3 & Elastic modulus & $71000 \mathrm{MPa}$ & $190000 \mathrm{MPa}$ \\
4 & Tensile ultimate strength & $310 \mathrm{MPa}$ & $970 \mathrm{MPa}$ \\
5 & Tensile yield strength & $280 \mathrm{MPa}$ & $660 \mathrm{MPa}$ \\
\hline
\end{tabular}

\subsection{Connections}

Regarding the contact between geometry parts of the release mechanism, the interface between bodies was given by using a joint connection type. Two types of connection joints were used, one is body-body with transnational type and the other one is the body - ground with revolute type. Stiffness behavior was taken as flexible. Tolerance type slider was considered with $1.0419 \mathrm{~mm}$ value.

\subsection{Loading conditions}

The load $L_{z}$ was applied on surface of hook where it comes in contact with lug of store, $L_{x}$ loads are applied on the fixed pins which are located beneath the outer dome and $L_{Y}$ loads are applied on the holes of outer dome (Where the mechanism is fixed to frame).

\section{Results}

After the application of loads, the process was set forth for structural analysis, for predicting strength and rigidity of the modified bomb release mechanism and supporting frame. The structural analysis considered here is static, modal, harmonics and kinematics. In static analysis, shear strain energy theory was considered to predict the stress of the structure and its results are illustrated in Figure.7(a \& b) and Figure.8(a \& b). For Fatigue Tool, Goodman Mean stress theory and Stress component equivalent (Von-Mises) were considered and its results are shown in Figure.7(c) and Figure.8(c).In the modal analysis, the Block Lanczos extraction method was used to know the natural frequency and mode shapes for both the Bomb release mechanism and its supporting frame structure and are tabulated in Table.6 and Table.7 respectively. For harmonic analysis, Mode Superposition Method was used to predict the sustained dynamic behavior for both the Bomb release mechanism and its supporting frame structure and are tabulated in Table. 8 and Table.9 respectively along with plotted graphs of amplitudes vs frequency in Figure.9.In the kinematic analysis, determining the right geometric arrangement of a grouping of parts undergoing dramatic translations and rotations is a complex task. Through ANSYS Rigid Dynamics kinematic analysis has been carried out. The time integration type used was Runge-Kutta 4. kinematic analysis is performed on BRM and the results considered are as follows: maximum total deformation is $8.809 e-3 \mathrm{~m}$, maximum total velocity is $0.017303 \mathrm{~m} / \mathrm{s}$ and maximum total acceleration is $0.016276 \mathrm{~m} / \mathrm{s}^{2}$. 


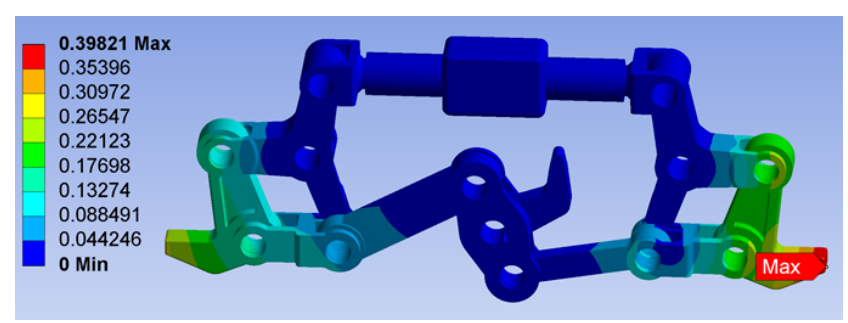

(a) Total Deformation

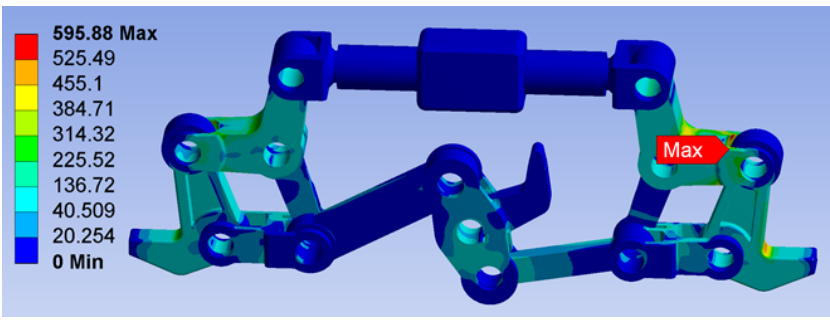

(b) Equivalent (von-Mises) Stress

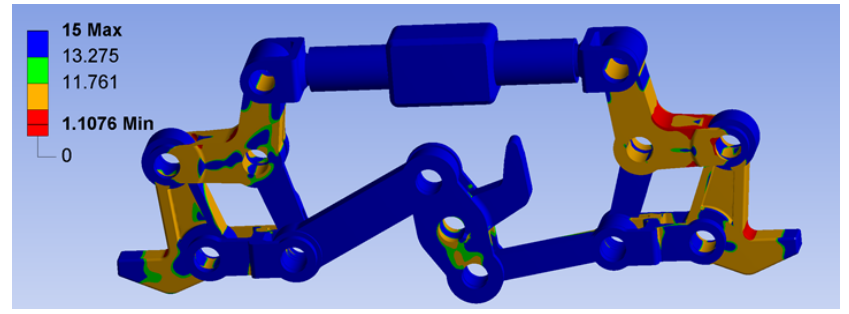

(c) Safety Factor - Mean Stress Theory - Goodman

Figure 7: Results of Static Analysis For BRM

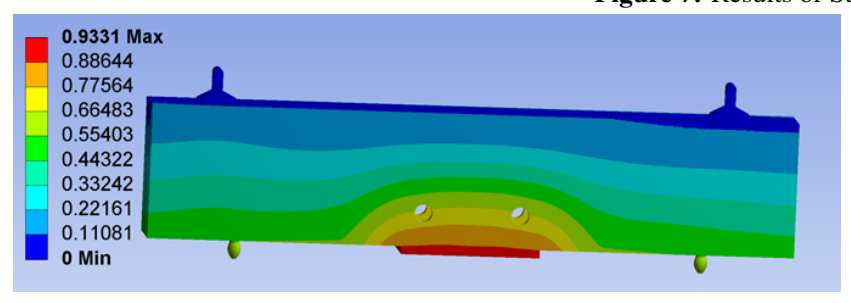

(a) Total deformation

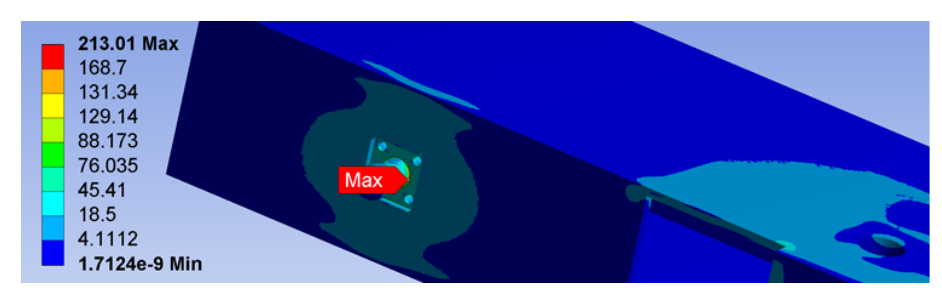

(b) Equivalent (von-Mises) Stress

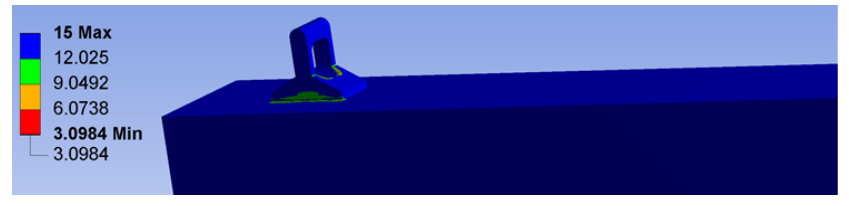

(c) Safety factor - Max equivalent Stress theory

Figure 8: Results of Static Analysis For Supporting Frame

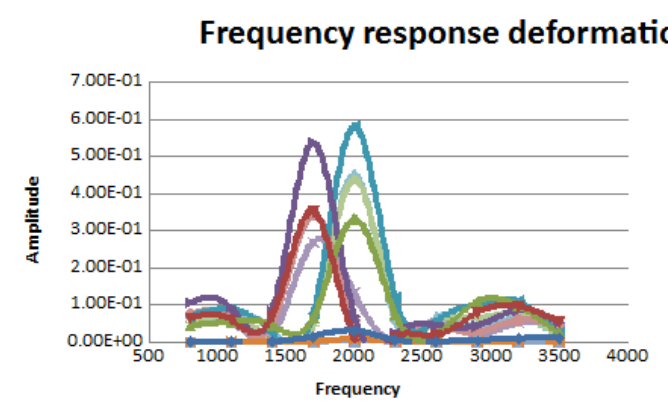

(a) Bomb release mechanism
Frequency response - deformation

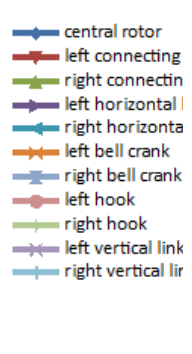

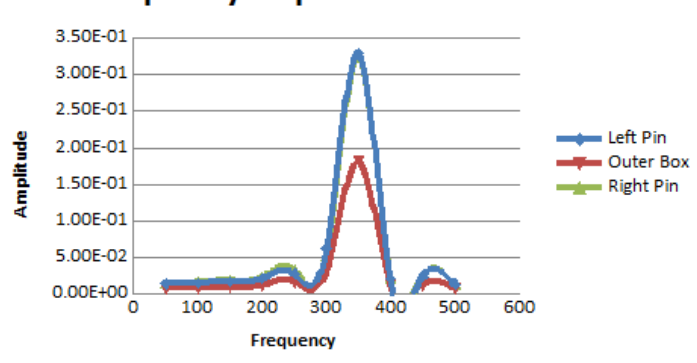

(b) Supporting Frame

Figure 9: Plotting amplitude vs frequency 
Table 6: Modes and their frequency of BRM

\begin{tabular}{|l|c|c|c|c|c|c|c|c|c|c|}
\hline Mode & 1 & 2 & 3 & 4 & 5 & 6 & 7 & 8 & 9 & 10 \\
\hline $\begin{array}{l}\text { Frequency } \\
{[\mathrm{Hz}]}\end{array}$ & 862.38 & 881.78 & 1332.5 & 1526.6 & 1656.5 & 1832.4 & 2046 & 2077.9 & 2094.2 & 2482 \\
\hline
\end{tabular}

Table 7: Modes and their frequency of Supporting Frame

\begin{tabular}{|l|c|c|c|c|c|c|c|c|c|c|}
\hline Mode & 1 & 2 & 3 & 4 & 5 & 6 & 7 & 8 & 9 & 10 \\
\hline $\begin{array}{l}\text { Frequency } \\
{[\mathrm{Hz}]}\end{array}$ & 62.662 & 134.08 & 196.84 & 280.62 & 318.05 & 319.17 & 343.07 & 413.54 & 447.05 & 475.37 \\
\hline
\end{tabular}

Table 8: Frequencies - Total Deformation for 10 Modes of BRM

\begin{tabular}{|c|c|c|c|c|c|c|c|c|c|c|}
\hline Mode & 1 & 2 & 3 & 4 & 5 & 6 & 7 & 8 & 9 & 10 \\
\hline Frequency $[\mathrm{Hz}]$ & 800 & 1100 & 1400 & 1700 & 2000 & 2300 & 2600 & 2900 & 3200 & 3500 \\
\hline
\end{tabular}

Table 9: Frequencies - Total Deformation for 10 Modes of the Supporting Frame

\begin{tabular}{|c|c|c|c|c|c|c|c|c|c|c|}
\hline Mode & 1 & 2 & 3 & 4 & 5 & 6 & 7 & 8 & 9 & 10 \\
\hline Frequency & 50 & 100 & 150 & 200 & 250 & 300 & 350 & 400 & 450 & 500 \\
\hline
\end{tabular}

\section{Discussions}

The results from simulation such as the distribution of Stress, strains, Deformation, Fatigue-Life of each component in a mechanism, natural frequencies, and corresponding vibration modes, are taken as reference. By neglecting localized stresses and all values when compared analytically are found to be appropriate. For example, let us consider Tensile yield strength (given input) of Grade 250 maraging steel, we want factor of safety as 1.15 ( $\max )$, therefore working stress is

$$
\frac{\text { maximum allowable stress }}{\text { factory of safety }}=\text { working stress }=660 / 1.15=573.913 \mathrm{MPa}
$$

As obtained working stress in static analysis is $595.88 \mathrm{MPa}$, but when neglecting the localized stress, the working stress ranges from 517.67 MPa to $439.46 \mathrm{MPa}$. Hence, the structure is capable of taking external loads and is in a safe condition. All the stresses are lower than the maximum analytical result and deformation value is considerably low, which satisfies the safety performance of mechanism upon application of load on hook, lugs, and pins of the outer dome of supporting frame. The weight of the Bomb Release Mechanism is $3.5868 \mathrm{~kg}$ and the dome is $35.658 \mathrm{~kg}$, the weight of sway brace with ejector is $24.93 \mathrm{~kg}$. Therefore total weight is $64.17 \mathrm{~kg}$ ( allowable up to $120 \mathrm{~kg}$ ). Hence this BRM structure with $64.17 \mathrm{~kg}$ was capable in terms of strength and operation. Therefore, the optimal weight of the structure was achieved.

\section{Conclusion}

In this work, an accurate rigid body dynamics model of the system is developed by building upon a detailed and accurate CAD model of the $\mathrm{BRM}$ and its associated interfaces. Relatively simple methods \& military standards are considered to set forth the structural and mechanical design criteria for BRM. Analysis methods specified in the military standards are referred for estimating key dynamical parameters of BRM, especially for estimation of the loads (actual, inertial and critical) and reaction forces at sway braces and hooks of suspension equipment. The model developed is extensively used for carrying out FE Analysis on practical systems of interest by following the conditions of static and dynamic (modal and harmonic) analysis. From the results, it can be clearly seen that the modified BRM provides desired performance meeting all the structural requirements.

Therefore, optimal design was achieved in terms of weight and space by modifying the existing design. The central rocker rotation was less i.e., from $90^{\circ}$ rotation to $75^{\circ}$ rotation when compared to considered reference design and also taking central rocker's axis as origin, links which are connected to this rocker has different lengths i.e., unsymmetrical design, which works and meets the principle objectives and requirements. Mechanical opening of hooks are synchronized properly. There was provision for safety lock which prevents from accidental release or opening of hooks. Also there was provision for manual release handle where ground operation for loading the store. It was concluded that, Structural strength was estimated and weight of release mechanism was lower than expected. It operates at different maneuvers with different loads acting on hooks which are synchronized mechanically and provides accurate symmetrical opening without any failure of components. Therefore, sustained dynamic behavior of structure was as predicted. Thus enabling design will successfully overcome stress deformation, fatigue and other effects of forced vibrations.

\section{Funding}

“This research received no external funding" 


\section{Conflicts of Interest}

"The authors declare no conflict of interest."

\section{Acknowledgement}

The authors are extremely thankful to Director, Defence Research \& Development Laboratory, Hyderabad and BrahMos team for their support and unfailing guidance throughout this long and arduous process.

\section{References}

[1] Dand Harvey Stewart, Grove Garden, and Calif. Store release mechanisms, March 27 1973. US3722944A.

[2] Paul F. Peterson, Rancho Palos Verdes, and Calif. Ejectorrack for nuclear stores, 201977. US4049222A.

[3] Thaddeus Jakubowski, Long Beach Jr., and Calif. Automatic sway bracing rack, January 15 1980. US4183480A.

[4] Steven D. Kay and Greenlawn. Low force bomb rack release mechanism, March 06 2012. US8127655B 1.

[5] Jean H. Hasquenoph and Pierre F. Coutin. Device for lockhng to fixed supports loads carered under aircraft, May 13 1980. US8127655B1.

[6] T. C. Schoppert. Dynamic model of the interface reactions in an aircraft bomb rack due to an external store. PhD thesis, West Virginia University, 2002

[7] DEPARTMENT OF DEFENSE DESIGN CRITERIA STANDARD. MILITARY SPECIFICATION:MIL-A-8591G AIRBORNE STORES, SUSPENSION EQt.lIP t4ENTAND AIRCRAFT-STORE INTERFACE (CARRIAGE PHASE): GENERAL DESIGN CRITERIA FOR. DEPARTMENT OF DEFENSE DESIGN CRITERIA STANDARD, 30 January 1979.

[8] DEPARTMENT OF DEFENSE DESIGN CRITERIA STANDARD. MIL-A-8591H(1):AIRBORNE STORES, SUSPENSION EQUIPMENT AND AIRCRAFT-STORE INTERFACE (CARRIAGE PHASE). DEPARTMENT OF DEFENSE DESIGN CRITERIA STANDARD, 30 JUnE 1994.

[9] DEPARTMENT OF DEFENSE DESIGN CRITERIA STANDARD. MIL-STD-2088B: BOMB RACK UNIT (BRU), AIRCRAFT. DEPARTMENT OF DEFENSE DESIGN CRITERIA STANDARD, 29 May 2007.

[10] R.K. Rajput. Strength of Materials: Mechanics of Solids. 